Article

\title{
High Performance Liquid Chromatography versus Stacking-Micellar Electrokinetic Chromatography for the Determination of Potentially Toxic Alkenylbenzenes in Food Flavouring Ingredients
}

\author{
Huynh N. P. Dang and Joselito P. Quirino * \\ Australian Centre for Research on Separation Science (ACROSS), School of Natural Sciences-Chemistry, \\ University of Tasmania, Hobart, TAS 7001, Australia; huynhngocphuong.dang@utas.edu.au \\ * Correspondence: jquirino@utas.edu.au
}

Citation: Dang, H.N.P.; Quirino, J.P. High Performance Liquid

Chromatography versus

Stacking-Micellar Electrokinetic Chromatography for the

Determination of Potentially Toxic

Alkenylbenzenes in Food Flavouring

Ingredients. Molecules 2022, 27, 13.

https://doi.org/10.3390/

molecules27010013

Academic Editor: Elisabetta

Torregiani

Received: 18 November 2021

Accepted: 15 December 2021

Published: 21 December 2021

Publisher's Note: MDPI stays neutral with regard to jurisdictional claims in published maps and institutional affiliations.

Copyright: (C) 2021 by the authors. Licensee MDPI, Basel, Switzerland. This article is an open access article distributed under the terms and conditions of the Creative Commons Attribution (CC BY) license (https:// creativecommons.org/licenses/by/ $4.0 /)$.
Abstract: Alkenylbenzenes, including eugenol, methyleugenol, myristicin, safrole, and estragole, are potentially toxic phytochemicals, which are commonly found in foods. Occurrence data in foods depends on the quality of the analytical methodologies available. Here, we developed and compared modern reversed-phase high performance liquid chromatography (HPLC) and stacking-micellar electrokinetic chromatography (MEKC) methods for the determination of the above alkenylbenzenes in food flavouring ingredients. The analytical performance of HPLC was found better than the stacking-MEKC method. Compared to other HPLC methods found in the literature, our method was faster (total run time with conditioning of $15 \mathrm{~min}$ ) and able to separate more alkenylbenzenes. In addition, the analytical methodology combining an optimized methanol extraction and proposed HPLC was then applied to actual food flavouring ingredients. This methodology should be applicable to actual food samples, and thus will be vital to future studies in the determination of alkenylbenzenes in food.

Keywords: alkenylbenzenes; food; high performance liquid chromatography; micellar electrokinetic chromatography

\section{Introduction}

The interest in alkenylbenzenes started in the 1960s, when safrole was found to cause tumours in rat liver [1]. Thereafter, other alkenylbenzenes have been studied to determine their hepatocarcinogenicity. In the early 2000s, the EU Scientific Committee on Food (EU-SCF) considered estragole, methyleugenol, and safrole as genotoxic and carcinogenic. Eugenol and myristicin are weak hepatocarcinogens, and the excessive consumption (e.g., >1 g) of myristicin can cause hallucinogenic effects due to its similar chemical structure to serotonin [2]. Thus, restrictions on the use of alkenylbenzenes as food additives have been recommended [3-5]. The EU maximum level is $1 \mathrm{mg} / \mathrm{kg}$ of safrole in foods and beverages. In the case of methyleugenol, estragole and other potentially toxic derivatives, the EU-SCF cannot establish their exposure limits in food [3-5]. Therefore, the margin of exposure approach had been used to assess the levels of some alkenylbenzenes in various food products [6-8].

There have been studies that indicated high levels of alkenylbenzenes in foods and beverages $[9,10]$. An issue with alkenylbenzenes is their widespread presence in many edible plants, which are typically used as spices/flavourings. Table 1 summarises the natural occurrence of alkenylbenzenes in this study (i.e., eugenol, methyleugenol, myristicin, safrole, and estragole) present in various edible plants/spices. A combination of the plants listed in Table 1 could potentially lead to high levels of the selected alkenylbenzenes in some foods. 
Table 1. Occurrence of eugenol, methyleugenol, myristicin, safrole, and estragole found in plants.

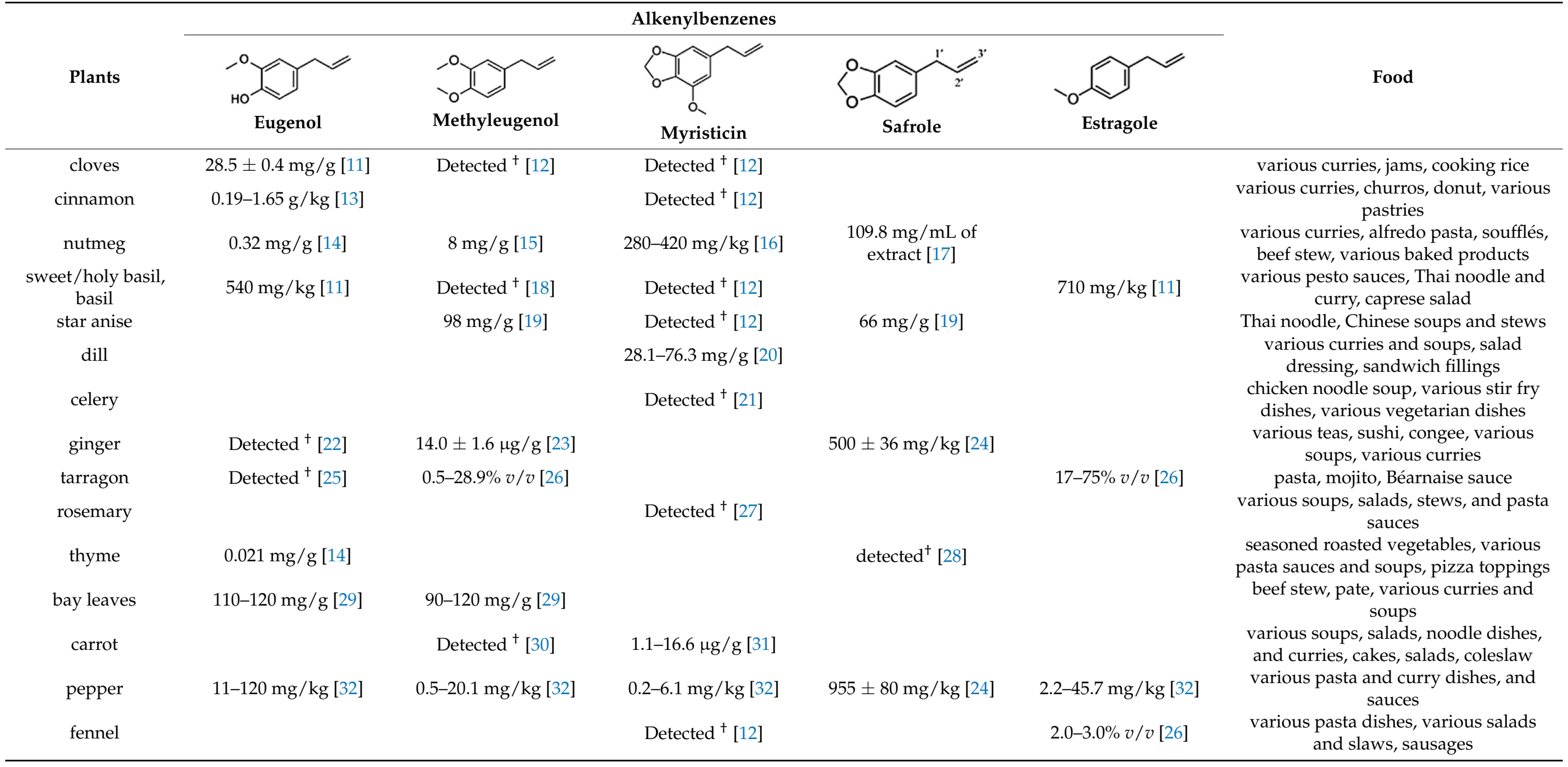

${ }^{+}$Detected but the actual amounts were not reported. 
Reliable analytical methods are extremely important in determining the occurrence of alkenylbenzenes in food. The data from these methods are used to assess the safety of food products and to calculate the total dietary intake. During the last decade, reported analytical methods for the determination of alkenylbenzenes in food and beverage samples have been mostly based on high-performance liquid chromatography (HPLC) [33]. The hydrophobic alkenylbenzenes were typically separated using a reversed-phase HPLC column and a mobile phase that contained an organic solvent. The analytes separate via their differential retention characteristics as they pass through the column that is pumped with a mobile phase. An alternative analytical separation technique to HPLC for alkenylbenzenes is micellar electrokinetic chromatography (MEKC) [34,35], which is a mode of capillary electrophoresis. Huhn and co-workers employed MEKC with negatively charged sodium dodecyl sulfate (SDS) micelles to separate the electrically neutral eugenol, safrole, methyleugenol, and myristicin in sassafras essential oil samples [36]. In MEKC, the micelles that were formed from SDS above the critical micelle concentration (CMC) acted as the chromatographic pseudophase. The analytes separate in the presence of an electric field, due to the differential migration of the alkenylbenzenes caused by their different affinities to the SDS micelles. MEKC is a greener technique compared to HPLC, but it suffers from poor detection limits [37]. Interestingly, very few studies compare the analytical performances of HPLC and MEKC or other separation techniques for the determination of potentially toxic phytochemicals found at low levels in our food chain [37-40].

Here, we developed and compared for the first time HPLC and MEKC methods for the determination of food flavouring ingredients. The reversed-phase HPLC method was developed by evaluation of three commercial columns and optimisation of the gradient conditions. MEKC with in-line sample concentration (stacking) method was developed by evaluation of natural bile salt micelles and optimisation of sample and background solution (BGS) conditions. The analytical performance of both methods was determined. Methanol $(\mathrm{MeOH})$ extraction, which has been shown to be an efficient and simple sample preparation technique for alkenylbenzenes [33] was then optimised to obtain the best recovery for actual samples. Real sample application of the selected analytical method was then demonstrated in the analysis of real food flavouring samples.

\section{Material and Methods}

\subsection{Standards and Reagents}

Chemicals used in this study (disodium hydrogen orthophosphate anhydrous, estragole, eugenol, methyleugenol, myristicin, $n$-nonyl- $\beta$-D-glycopyranoside safrole, sodium cholate, SDS, sodium phosphate monobasic dihydrate and trifluoroacetic acid (TFA)) were obtained from Sigma-Aldrich (Castle Hill, New South Wales, Australia). Purified water was obtained from a Milli-Q system (Millipore, MA, USA). The organic solvents acetonitrile $(\mathrm{ACN})$, acetone, ethanol $(\mathrm{EtOH})$ and methanol $(\mathrm{MeOH})$ were HPLC or analytical grade and obtained from Sigma-Aldrich (St. Louis, MO, USA).

For HPLC analysis, mobile phases were prepared by adding appropriate volumes of TFA to purified water or ACN. Prior to use, mobile phases were sonicated and filtered with $0.45 \mu \mathrm{m}$ filter (Millipore, MA, USA). Each stock standard solution ( $5 \mathrm{~mL}$ ) was prepared by mixing $5 \mu \mathrm{L}$ of the analyte with $4.995 \mathrm{~mL}$ of $80 \% \mathrm{MeOH}$. The solutions were sonicated and stored at $2-8{ }^{\circ} \mathrm{C}$. The resulting concentrations were $1.061 \mathrm{mg} / \mathrm{mL}$ (eugenol), $1.040 \mathrm{mg} / \mathrm{mL}$ (methyleugenol), $1.140 \mathrm{mg} / \mathrm{mL}$ (myristicin), $0.970 \mathrm{mg} / \mathrm{mL}$ (estragole), and $1.101 \mathrm{mg} / \mathrm{mL}$ (safrole). Standard solutions for injection were prepared by mixing appropriate volumes of the stock solution and 50\% $\mathrm{MeOH}$.

For MEKC analysis, stock solutions of $200 \mathrm{mM}$ phosphate buffer (pH 11), $400 \mathrm{mM}$ sodium cholate and $0.1 \mathrm{M} \mathrm{NaOH}$ were prepared in purified water. Phosphate buffer was prepared by mixing appropriate amounts of disodium hydrogen orthophosphate anhydrous and sodium phosphate monobasic dihydrate in purified water. The $\mathrm{pH}$ of phosphate buffer was adjusted using $0.1 \mathrm{M} \mathrm{NaOH}$. Prior to use, all solutions were sonicated and filtered with a $0.45 \mu \mathrm{m}$ disposable nylon filter. Background solution (BGS) were 
prepared by mixing the phosphate buffer, sodium cholate, acetone, and purified water at appropriate volumes. Stock solutions of analytes were prepared in $15 \mathrm{mM}$ SDS and stored at $2-8{ }^{\circ} \mathrm{C}$.

\subsection{Instrumentation and Software}

Reversed-phase HPLC was performed using a Dionex HPLC system, consisting of Ultimate 300 pump, Ultimate 300 Colum Compartment and Ultimate 3000 diode array detector and an Ultimate 300 autosampler (Sunnyvale, CA, USA). A GEMINI C18 (150 mm $\times 2.4 \mathrm{~mm}$ i.d., $5 \mu \mathrm{m}$ particle size) from Phenomenex (Lane Cove West, NSW, Australia) was used as chromatographic column. Data acquisition was performed using Chromeleon 7.2.7 software (Sunnyvale, CA, USA). MEKC was conducted using the Agilent 3-D CE system (Agilent, Santa Clara, CA, USA), with $50 \mu \mathrm{m}$ inner diameter and $375 \mu \mathrm{m}$ outer diameter fused-silica capillary (Polymicro, Phoenix, AZ, USA). The effective capillary length was $29 \mathrm{~cm}$ (total length was $37.5 \mathrm{~cm}$ ).

\subsection{Sample Preparation}

A $1 \mathrm{~g}$ of sauce or $0.2 \mathrm{~g}$ of dry plant material (e.g., leaf) sample was weighed in a $20 \mathrm{~mL}$ glass vial. $10 \mathrm{~mL}$ methanol was added to the sample and the mixture was sonicated for $15 \mathrm{~min}$. A few ice cubes were added to the sonicator bath to maintain the water at room temperature. Then, $1 \mathrm{~mL}$ of the methanol extract was centrifuged for $5 \mathrm{~min}$ at $1000 \mathrm{rpm}$. The supernatant was filtered through a $0.45 \mu \mathrm{m}$ nylon filter and then diluted 1:1 with purified water prior to HPLC analysis.

\subsection{Reversed-Phase HPLC Conditions}

The compounds were separated using a gradient mobile phase consisting of $0.1 \%(v / v)$ TFA in purified water (solvent $\mathrm{A}$ ) and $0.1 \%(v / v)$ TFA in ACN (solvent B). Gradient conditions were: $0.0-1.0 \mathrm{~min}, 50 \% \mathrm{~B} ; 1.0-13.0 \mathrm{~min}, 50-70 \% \mathrm{~B} ; 13.0-14.0 \mathrm{~min}, 70 \% \mathrm{~B} ; 14.0-15.0 \mathrm{~min}$, $70-50 \% \mathrm{~B}$; and $15.0-20.0 \mathrm{~min}, 50 \% \mathrm{~B}$. Flow rate was $1.0 \mathrm{~mL} / \mathrm{min}$. The injection volume was $20 \mu \mathrm{L}$. The column temperature was maintained at $25^{\circ} \mathrm{C}$. The detection wavelength was set at $280 \mathrm{~nm}$.

\subsection{MEKC Analysis}

A new capillary was conditioned with purified water, $0.1 \mathrm{M} \mathrm{NaOH}$, purified water and BGS for 10, 30, 10, and $30 \mathrm{~min}$, respectively. At the beginning of each testing day, the capillary was flushed with purified water for $5 \mathrm{~min}, 0.1 \mathrm{M} \mathrm{NaOH}$ for $10 \mathrm{~min}$, purified water for $5 \mathrm{~min}$ and BGS for $10 \mathrm{~min}$. In between runs, the capillary was flushed with purified water, $0.1 \mathrm{M} \mathrm{NaOH}$, purified water and BGS for 1, 3, 1, 6 min, respectively. The detection wavelength was set at $200 \mathrm{~nm}$. The capillary temperature was maintained at $20^{\circ} \mathrm{C}$. Stacking injection was by pressure at $50 \mathrm{mbar}$ for $25 \mathrm{~s}$.

\section{Results and Discussion}

\subsection{Reversed-Phase HPLC Method Development}

The commercial analytical columns with the manufacturer's recommended flow rate and injection volume used in this study are summarised in Table 2. Separations were evaluated using gradient elution with increasing concentrations of can in the mobile phase (increasing \% of mobile phase B). The results indicated better separation performance with the Phenomenex GEMINI C18 column and thus the gradient conditions for this column were further optimised. Figure 1 shows the effect of the $\% \mathrm{ACN}$ in the initial mobile phase on the separation of the alkenylbenzenes. The gradient conditions were: $0.0-1.0 \mathrm{~min}, \% \mathrm{~B}$ (20\%, 30\%, 40\%, 50\%); $1.0-13.0 \mathrm{~min}, 70 \%$ B; $13.0-14.0 \mathrm{~min}, 70 \% \mathrm{~B} ; 14.0-15.0 \mathrm{~min}, \%$ B (20\%, $30 \%, 40 \%, 50 \%)$. The column was conditioned with the initial mobile phase condition for 5 min prior to each sample injection. The \% ACN at the start of the run in Figure $1 \mathrm{~A}-\mathrm{D}$ was $50 \%, 40 \%, 30 \%$, and $20 \%$, respectively. The separations were similar with all the conditions used but faster analysis was achieved with $50 \%$ (c) at the start of the run. All 
analytes were successfully separated. The identification of the peaks was performed by running individual analytes and by increasing the concentration of one analyte at a time in the standards mixture. The gradient condition in Figure 1A was then chosen with a run time (including conditioning) of $15 \mathrm{~min}$. Compared to other reversed-phase HPLC methods reported in the literature [33], our method was faster and able to separate more alkenylbenzenes.

Table 2. Characteristics for the three tested commercial reversed-phase HPLC columns.

\begin{tabular}{cccc}
\hline Column. & Specifications (Particle Size) & $\begin{array}{c}\text { Flow Rate } \\
(\mathbf{m L} / \mathbf{m i n})\end{array}$ & $\begin{array}{c}\text { Injection } \\
\text { Volume }(\mu \mathrm{L})\end{array}$ \\
\hline $\begin{array}{c}\text { Thermo Fischer Hypersil } \\
\text { GOLD C18 }\end{array}$ & $50 \mathrm{~mm} \times 2.1 \mathrm{~mm}$ i.d. $(3 \mu \mathrm{m})$ & 0.2 & 5 \\
$\begin{array}{c}\text { Acclaim C18 } \\
\text { Phenomenex GEMINI } \\
\text { C18 }\end{array}$ & $100 \mathrm{~mm} \times 2.1 \mathrm{~mm}$ i.d. $(2.2 \mu \mathrm{m})$ & 0.5 & 10 \\
\hline
\end{tabular}

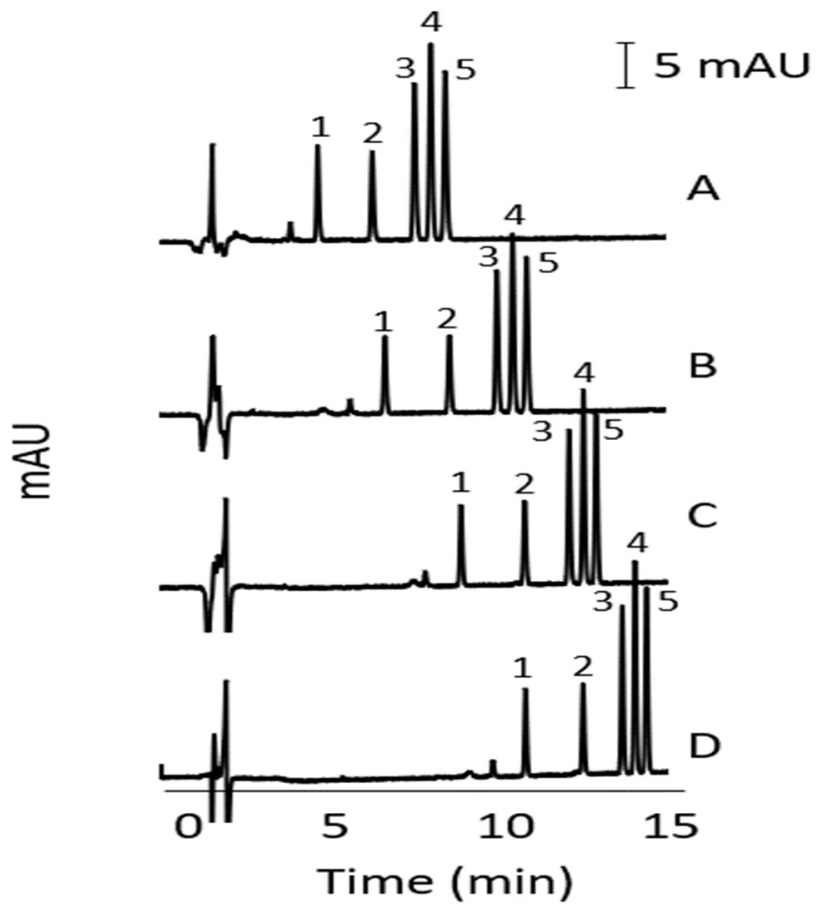

Figure 1. HPLC of alkenylbenzenes using different gradient conditions. \% ACN in the initial mobile phase was 50\%B (A), 40\%B (B), 30\% B (C), and 20\% B (D). Other conditions are described in Sections 2.4 and 3.1. Peak identity: eugenol (1), methyleugenol (2), myristicin (3), safrole (4), and estragole (5). Concentration of analytes $(\mu \mathrm{g} / \mathrm{mL})$ : eugenol (3.5), methyleugenol (0.9), myristicin (20.3), safrole (8.5), and estragole (18.2).

\subsection{Stacking-MEKC Method Development}

MEKC separations using SDS micelles in acidic and basic media and from various bile salts in neutral to basic media were investigated. Note that bile salts are only soluble in neutral to basic media. The most promising results were obtained using a BGS containing sodium cholate in $100 \mathrm{mM}$ sodium phosphate buffer ( $\mathrm{pH} 11)$, thus the BGS with sodium cholate in the $\mathrm{pH} 11$ buffer was further optimised. Figure 2 shows the effect of sodium cholate concentration $(25,50,100 \mathrm{mM})$ on the MEKC separation of the alkenylbenzenes at $\mathrm{pH}$ 11. With $100 \mathrm{mM}$ sodium cholate in the BGS (see Figure 2C), compete separation of eugenol and methyleugenol (peaks 1 and 2) was achieved, but there was only partial separation of myristicin, estragole, and safrole (peaks 3, 4 and 5). 


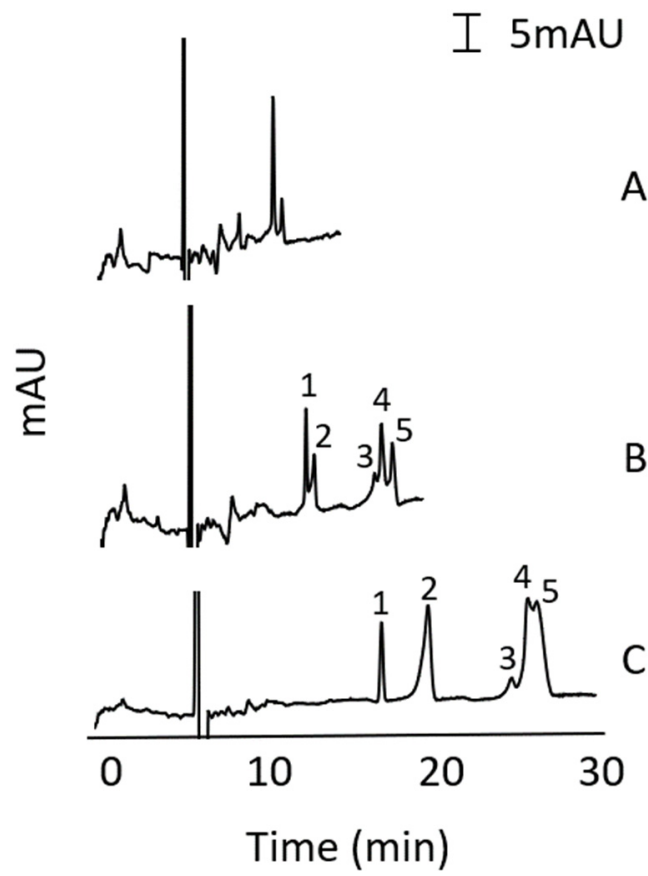

Figure 2. Effect of sodium cholate concentration in the MEKC separation of five alkenylbenzenes. BGS was $25 \mathrm{mM}$ (A), $50 \mathrm{mM}$ (B), and $100 \mathrm{mM}$ (C) sodium cholate and $100 \mathrm{mM}$ sodium phosphate buffer ( $\mathrm{pH} 11)$. Injection was by pressure at $25 \mathrm{mbar}$ for $5 \mathrm{~s}$. Other conditions were described in Section 2.5. Peak identity: eugenol (1), methyleugenol (2), myristicin (3), estragole (4) and safrole (5). Concentration of analytes ( $\mu \mathrm{g} / \mathrm{mL})$ : eugenol (4.6), methyleugenol (3.6), myristicin (31.4), safrole (17.7), and estragole (18.2).

Various additives to the BGS containing $100 \mathrm{mM}$ sodium cholate and $100 \mathrm{mM}$ sodium phosphate buffer ( $\mathrm{pH} 11$ ) were then studied to improve the MEKC separation. The additives were a non-ionic surfactant (n-nonyl- $\beta$-D-glycopyranoside) and various organics solvents including $\mathrm{MeOH}$, acetone, $\mathrm{EtOH}$ and $\mathrm{ACN}$ at different concentrations. The best result for each additive is shown in Figure 3 using $10 \mathrm{mM}$ non-ionic surfactant $(\mathrm{A}), 3 \% \mathrm{MeOH}$ (B), 3.5\% acetone (C), 3\% EtOH (D) and 3\% ACN (E). Among the conditions presented in Figure 3, the separation of all peaks was obtained with 3.5\% acetone (see Figure 3C) in the BGS.

\subsection{Stacking Method Development in MEKC}

Using the conditions described for Figure 3C, different stacking conditions were tested to increase the peak heights of the analytes without compromise to the separation performance. To evaluate the stacking, the sample solutions prepared in different diluents were injected as a long plug ( $50 \mathrm{mbar}$ for $25 \mathrm{~s}$ ) (see Figure $4 \mathrm{~A}-\mathrm{C}$ ). The typical injection which was $1 / 10 \times$ shorter than the stacking injection is shown in Figure $4 \mathrm{D}$ for comparison. The concentration of the analytes in the stacking injections were $10 \times$ lower than in the typical injection. The sample diluent in Figure $4 \mathrm{~A}$ was $10 \% \mathrm{MeOH}$ in $100 \mathrm{mM}$ sodium phosphate buffer ( $\mathrm{pH} 11$ ) to induce stacking via sweeping [41,42]. The sample diluent in Figure 4B was $10 \% \mathrm{MeOH}$ in purified water and in Figure 4C was $15 \mathrm{mM}$ SDS in purified water to produce stacking by field enhancement [43] and field enhancement with SDS micelles [44], respectively. Note that the CMC of SDS in water is $8 \mathrm{mM}$. Among the tested stacking techniques, field enhancement with SDS micelles was found most effective (see Figure 4C). 


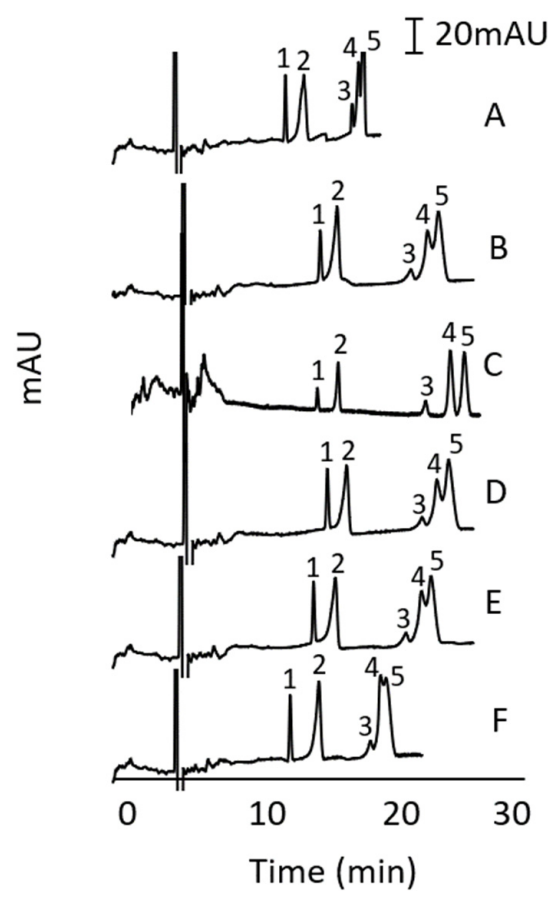

Figure 3. Effect of different additives on the MEKC of alkenylbenzenes. BGS was $10 \mathrm{mM}$ n-nonyl- $\beta$ D-glycopyranoside (A), 3\% methanol (B), 3.5\% acetone (C), 3\% ethanol (D), 3\% acetonitrile (E), and no additive (F), $100 \mathrm{mM}$ sodium cholate and $100 \mathrm{mM}$ phosphate buffer ( $\mathrm{pH} 11)$. Concentration of analytes ( $\mu \mathrm{g} / \mathrm{mL}$ ): eugenol (7.9), methyleugenol (8.7), myristicin (35.8), safrole (26.4), and estragole (18.2). Other conditions and peak identity were the same as in Figure 2.

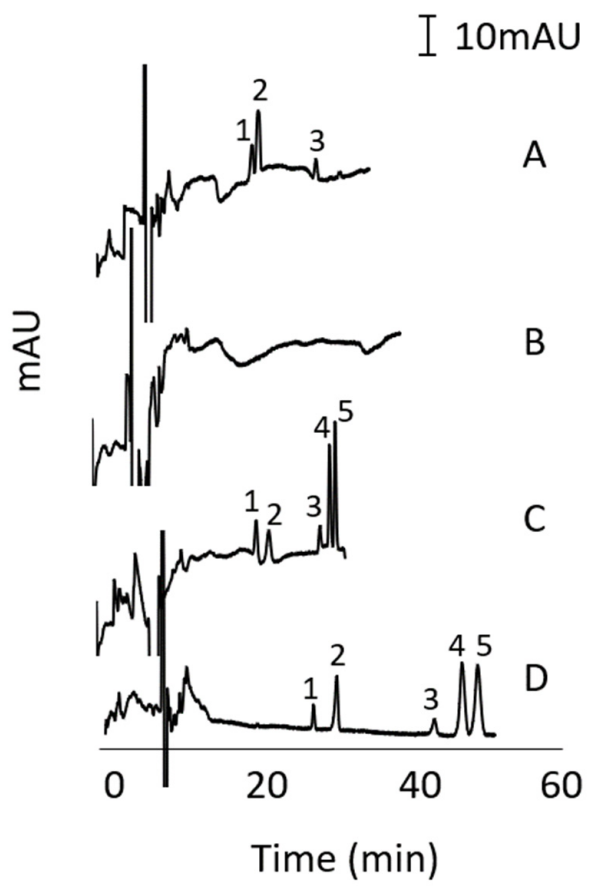

Figure 4. Effect of different sample diluents in the stacking-MEKC of alkenylbenzenes. Sample diluents were $10 \% \mathrm{MeOH}$ in phosphate buffer (A), 10\% $\mathrm{MeOH}$ in water (B), $15 \mathrm{mM}$ SDS in water (C), and no diluent (D) in 3.5\% acetone with $100 \mathrm{mM}$ sodium cholate and $100 \mathrm{mM}$ phosphate buffer $(\mathrm{pH}$ 11). Stacking injection was by pressure at 50 mbar for $25 \mathrm{~s}$ in (A-C). Typical injection was by pressure at $25 \mathrm{mbar}$ for $5 \mathrm{~s}$ in (D). Concentration of analytes ( $\mu \mathrm{g} / \mathrm{mL})$ in (D): eugenol (7.9), methyleugenol (8.7), myristicin (35.8), safrole (26.4), and estragole (18.2). Concentration of analytes $(\mu \mathrm{g} / \mathrm{mL})$ in $(\mathbf{A}-\mathbf{C}): 1 / 10$ of the concentrations in $(\mathbf{D})$. Other conditions and peak identity were the same as in Figure 2. 
The stacking via field enhancement with SDS micelles was caused by the change in the effective electrophoretic velocity of the analytes (that are solubilised by the SDS micelles) at the boundary between the sample and BGS zones. The effective electrophoretic velocity of the analytes in the sample zone was faster than that in the BGS zone. The sudden decrease in the effective electrophoretic velocity caused the enrichment of the analytes at the boundary. The sensitivity enhancement factor (SEF) for each analyte was calculated by dividing the peak height obtained in typical injection by the peak height obtained in stacking injection, then multiplied by the dilution factor $(=10)$. For the results in Figure $4 \mathrm{C}$, the SEF values for eugenol, methyleugenol, myristicin, estragole, and safrole were 11, 5, 13, 8 , and 12 , respectively. Longer than $25 \mathrm{~s}$ injection of $50 \mathrm{mbar}$ caused the co-migration of the last three peaks. Thus, the optimum stacking-MEKC conditions are those described for Figure $4 \mathrm{C}$.

\subsection{HPLC and Stacking-MEKC Comparison of Analytical Figures of Merit}

The analytical figures of merit obtained for the optimised HPLC (conditions in Figure 1A) and stacking-MEKC (conditions in Figure 4C) are summarised in Table 3.

Table 3. Linear regression data for calibration curves.

\begin{tabular}{|c|c|c|c|c|c|c|}
\hline Method & & Eugenol & Methyleugenol & Myristicin & Safrole & Estragole \\
\hline \multirow[t]{6}{*}{ HPLC } & $\begin{array}{l}\text { concentration } \\
\text { range }(\mu \mathrm{g} / \mathrm{mL})\end{array}$ & $0.18-12$ & $0.07-4.3$ & $0.79-50$ & $0.36-23$ & $0.73-46$ \\
\hline & slope of the line & 251.27 & 1005.70 & 84.26 & 261.06 & 108.30 \\
\hline & $\begin{array}{l}\text { intercept of the } \\
\text { line }\end{array}$ & -0.0169 & -0.0171 & -0.0162 & -0.0310 & -0.0362 \\
\hline & $\begin{array}{c}\text { correlation } \\
\text { coefficient }\left(R^{2}\right)\end{array}$ & 0.9970 & 0.9967 & 0.9966 & 0.9968 & 0.9965 \\
\hline & $\mathrm{LOD}(\mu \mathrm{g} / \mathrm{mL})$ & 0.09 & 0.03 & 0.39 & 0.18 & 0.36 \\
\hline & LOQ $(\mu \mathrm{g} / \mathrm{mL})$ & 0.18 & 0.07 & 0.79 & 0.36 & 0.73 \\
\hline \multirow{6}{*}{$\begin{array}{l}\text { stacking } \\
\text { MEKC }\end{array}$} & $\begin{array}{l}\text { concentration } \\
\text { range }(\mu \mathrm{g} / \mathrm{mL})\end{array}$ & $1.6-50$ & $1.5-24$ & $3.7-29$ & $7.1-21$ & $6.0-37$ \\
\hline & slope of the line & 8590.2 & 6087.6 & 595.87 & 3020.2 & 1537.7 \\
\hline & $\begin{array}{l}\text { intercept of the } \\
\text { line }\end{array}$ & -13.801 & +3.279 & +0.374 & -22.81 & -10.36 \\
\hline & $\begin{array}{c}\text { correlation } \\
\text { coefficient }\left(R^{2}\right)\end{array}$ & 0.9972 & 0.9947 & 0.9964 & 0.9724 & 0.9975 \\
\hline & $\mathrm{LOD}(\mu \mathrm{g} / \mathrm{mL})$ & 0.41 & 0.38 & 1.8 & 2.7 & 4.3 \\
\hline & LOQ $(\mu \mathrm{g} / \mathrm{mL})$ & 1.6 & 1.5 & 3.7 & 7.1 & 6.0 \\
\hline
\end{tabular}

\subsubsection{Linearity}

The reversed-phase HPLC method showed a good relationship between the tested concentrations of standard solutions and the corresponding peak areas. The linear ranges were $\sim 2$ orders of concentration magnitude (see Table 3). The correlation coefficients $\left(\mathrm{R}^{2} \mathrm{~s}\right)$ for the calibration graphs/lines were all $>0.997$, which were above the typically recommended requirement for $\mathrm{R}^{2}$ of $>0.995$, whereas in $\mathrm{MEKC}$, the linear ranges using corrected peak area (peak area/migration time) for myristicin, safrole, and estragole were $<1$ order of concentration magnitude and the $\mathrm{R}^{2}$ for safrole was unacceptable or 0.972 . Therefore, only the HPLC method passed the requirements of the linearity study.

\subsubsection{LOD and LOQ}

The LOD and LOQ values were determined using a signal-to-noise $(\mathrm{S} / \mathrm{N})$ ratio of 3 and 10 , respectively (see Table 3$)$. The LOQ $(S / N=10)$ values were also verified as the lowest concentration in the determined linear ranges. The LOQ values in HPLC were in the range between 0.07 and $0.79 \mu \mathrm{g} / \mathrm{mL}$. The LOQ values in stacking-MEKC were at least an order of magnitude higher compared to HPLC. The values in stacking-MEKC 
ranged between 1.5 and $7.1 \mu \mathrm{g} / \mathrm{mL}$. In summary, the HPLC was more sensitive than the stacking-MEKC method.

\subsubsection{Intra- and Inter-Day Repeatability}

The intra- and inter-day repeatability was assessed using two concentration levels (i.e., LOQ and $8 \times$ LOQ). For intra-day repeatability, each concentration level was analysed in 10 replicates $(n=10)$, which were performed during a day. For inter-day repeatability, each concentration level was analysed in 5 replicates in a day, for 3 consecutive days $(n=15)$. The percentage RSD values obtained in HPLC and stacking-MEKC are summarised in Table 4. At the LOQ and $8 \times$ LOQ, the HPLC method showed excellent repeatability for retention time with intra- and inter-day repeatability percentage RSDs that ranged from 0.1 to $0.4 \%$. For peak areas in HPLC, the intra-day repeatability percentage RSDs ranged from 0.0 to $4.0 \%$, while inter-day repeatability percentage RSDs ranged from 0.0 to $7.0 \%$. The intra- and inter-day repeatability percentage RSDs for migration time in stackingMEKC ranged from 1.3 to $5.2 \%$. In stacking-MEKC, the intra-day repeatability \% RSDs for corrected peak area ranged from 0.4 to $5.0 \%$, while the values for inter-day ranged from 0.3 to $7.8 \%$. In general, the HPLC was more repeatable than the stacking-MEKC method. Therefore, the HPLC method was used for the optimisation of the MeOH extraction method for food samples.

Table 4. Intra- and inter-day repeatability of HPLC and stacking-MEKC methods.

\begin{tabular}{|c|c|c|c|c|c|c|c|}
\hline \multirow{2}{*}{ Method } & & \multirow{2}{*}{ Analyte } & \multirow{2}{*}{$\begin{array}{l}\text { Concentration } \\
\text { Levels } \\
(\mu \mathrm{g} / \mathrm{mL})\end{array}$} & \multicolumn{2}{|c|}{$\begin{array}{l}\text { \% RSD (Retention Time } \\
\text { 1/Migration Time }{ }^{2} \text { ) }\end{array}$} & \multicolumn{2}{|c|}{$\begin{array}{c}\% \text { RSD (Peak Area/Corrected } \\
\text { Peak Area }{ }^{5} \text { ) }\end{array}$} \\
\hline & & & & $\begin{array}{c}\text { Intra-Day } \\
(\mathrm{n}=10)^{3}\end{array}$ & $\begin{array}{c}\text { Inter-Day } \\
(\mathrm{n}=15)^{4}\end{array}$ & $\begin{array}{c}\text { Intra-Day } \\
(n=10)^{3}\end{array}$ & $\begin{array}{c}\text { 1nter-Day } \\
(\mathrm{n}=15)^{4}\end{array}$ \\
\hline \multirow{10}{*}{ HPLC } & \multirow{5}{*}{ LOQ } & Eugenol & 0.2 & 0.2 & 0.4 & 4.0 & 3.3 \\
\hline & & methyleugenol & 0.1 & 0.1 & 0.4 & 3.8 & 3.9 \\
\hline & & myristicin & 0.8 & 0.2 & 0.5 & 0.0 & 0.0 \\
\hline & & safrole & 0.4 & 0.1 & 0.4 & 0.0 & 3.3 \\
\hline & & estragole & 0.7 & 0.1 & 0.4 & 3.2 & 1.7 \\
\hline & \multirow{5}{*}{$\begin{array}{c}8 \times \\
\text { LOQ }\end{array}$} & eugenol & 1.4 & 0.4 & 0.3 & 0.7 & 1.1 \\
\hline & & methyleugenol & 5.4 & 0.4 & 0.3 & 0.5 & 0.9 \\
\hline & & myristicin & 6.3 & 0.3 & 0.3 & 0.0 & 0.1 \\
\hline & & safrole & 2.9 & 0.3 & 0.3 & 0.0 & 3.5 \\
\hline & & estragole & 5.8 & 0.3 & 0.3 & 0.5 & 7.0 \\
\hline \multirow{10}{*}{$\begin{array}{l}\text { stacking- } \\
\text { MEKC }\end{array}$} & \multirow{5}{*}{ LOQ } & eugenol & 1.6 & 2.9 & 4.4 & 0.6 & 0.8 \\
\hline & & methyleugenol & 1.5 & 2.9 & 5.2 & 0.4 & 0.3 \\
\hline & & myristicin & 3.7 & 2.4 & 2.0 & 1.1 & 3.0 \\
\hline & & safrole & 7.1 & 1.5 & 1.4 & 3.4 & 3.6 \\
\hline & & estragole & 6.0 & 1.8 & 1.6 & 5.0 & 6.3 \\
\hline & \multirow{5}{*}{$\begin{array}{c}8 \times \\
\text { LOQ }\end{array}$} & eugenol & 13.0 & 1.3 & 1.6 & 4.8 & 1.1 \\
\hline & & methyleugenol & 6.1 & 3.2 & 1.7 & 0.7 & 1.9 \\
\hline & & myristicin & 15.0 & 1.9 & 3.8 & 0.4 & 2.1 \\
\hline & & safrole & 11.0 & 1.4 & 1.9 & 4.4 & 6.1 \\
\hline & & estragole & 18.0 & 2.4 & 2.5 & 4.8 & 7.8 \\
\hline
\end{tabular}

${ }^{1}$ Retention time was used in HPLC. ${ }^{2}$ Migration time was used in stacking-MEKC. ${ }^{3}$ Each concentration level was replicated 10 times within a day. ${ }^{4}$ Each concentration level was replicated 5 times within a day, for 3 consecutive days. ${ }^{5}$ Corrected peak area was used in stacking-MEKC, corrected peak area $=$ peak area $/$ migration time. This was because of the different effective electrophoretic velocities of the analytes in MEKC.

\subsection{Optimisation of Sample Preparation via $\mathrm{MeOH}$ Extraction}

The sample preparation via $\mathrm{MeOH}$ extraction was initially optimised using a commercial dried basil leaves sample. The dried basil leaves sample contained 3 of the 5 alkenylbenzenes (eugenol, methyleugenol and estragole). The extraction described by Gursale et al. [45] was modified and optimized to provide the best recovery. The effect of $\mathrm{MeOH}$ 
volume during extraction was first investigated. Briefly, a $0.2 \mathrm{~g}$ sample was extracted with $5,10,15$, or $20 \mathrm{~mL}$ of $\mathrm{MeOH}$. The sample was sonicated for $15 \mathrm{~min}$ and centrifuged for $5 \mathrm{~min}$. The supernatant was filtered and then diluted 1:1 with purified water prior to HPLC analysis. Corrected peak area was calculated by dividing the peak area with the volume of $\mathrm{MeOH}$ used. The best extraction was obtained using $10 \mathrm{mM}$ of $\mathrm{MeOH}$, as it provided the highest corrected peak areas among all the volumes studied. The sonication times of $5,10,15$, and $20 \mathrm{~min}$ were then studied. The HPLC peak areas for the analytes increased gradually when the sonication time was increased from 5 to $15 \mathrm{~min}$, then was similar when the time was 15 and $20 \mathrm{~min}$. The $15 \mathrm{~min}$ was then considered as the optimum sonication time.

\subsection{Recovery}

Recovery studies were conducted using two samples and by standard addition method. For myristicin and safrole, dried basil leaves sample were used as they only contain eugenol, methyleugenol, and estragole. For eugenol, methyleugenol and estragole, dried oregano leaves were used. The samples were spiked or fortified with known amounts of the alkenylbenzenes (7 concentration levels). Extraction of triplicate samples with $10 \mathrm{~mL}$ of $\mathrm{MeOH}, 15$ min sonication time and sample dilution were carried out as described in Section 3.5. Percentage recovery values were calculated by dividing the found concentration by the nominal concentration, then multiplied by $100 \%$. The nominal concentration was the sum of the analyte concentration in the sample and the added concentration. The results are summarized in Table 5, which shows the analyte concentration in the sample, added concentration, nominal concentration, found concentration, and percentage recovery values. The highest percentage recovery values of 69.4 to $91.1 \%$ were achieved with eugenol. The values for the other alkenylbenzenes ranged from 57.1 to $81.4 \%$. These values seem to be suitable for the determination of alkenylbenzenes for application to food samples.

\subsection{Method Application}

The optimised analytical method utilizing $\mathrm{MeOH}$ extraction and reversed-phase HPLC analysis was applied to the determination of the 5 alkenylbenzenes in fresh basil leaves, Galiko basil sauce (38\% basil leaves), and cloves. The results obtained from three replicate analysis of each sample are summarised in Table 6. As expected, the highest eugenol content was found in cloves with $8.71 \pm 0.09 \mathrm{mg} / \mathrm{g}$, whereas methyleugenol and estragole were detected at the highest levels in basil leaves with $0.07 \pm 0.01$ and $0.72 \pm 0.11 \mathrm{mg} / \mathrm{g}$, respectively. A representative HPLC chromatogram for each sample is shown in Figure 5A-C. Figure 5D is HPLC of a standard mix for comparison. The targeted analytes seem to be well separated from the other components found in the tested real samples. 
Table 5. Percentage recovery study results in the $\mathrm{MeOH}$ extraction and reversed-phase HPLC analysis of the five alkenylbenzenes in fortified real samples.

\begin{tabular}{|c|c|c|c|c|c|}
\hline Analyte & $\begin{array}{c}\text { Sample } \\
\text { Concentration } \\
(\mu \mathrm{g} / \mathrm{mL})\end{array}$ & $\begin{array}{c}\text { Added } \\
\text { Concentration } \\
(\mu \mathrm{g} / \mathrm{mL})\end{array}$ & $\begin{array}{c}\text { Nominal } \\
\text { Concentration } \\
(\mu \mathrm{g} / \mathrm{mL})\end{array}$ & $\begin{array}{c}\text { Found } \\
\text { Concentration } \\
(\mu \mathrm{g} / \mathrm{mL})\end{array}$ & \% Recovery \\
\hline \multirow{7}{*}{ eugenol } & \multirow{7}{*}{1.08} & 0.54 & 1.62 & $1.32 \pm 0.00$ & $81.5 \pm 0.0$ \\
\hline & & 1.08 & 2.16 & $1.79 \pm 0.00$ & $82.9 \pm 0.0$ \\
\hline & & 2.16 & 3.24 & $2.75 \pm 0.01$ & $84.9 \pm 0.0$ \\
\hline & & 4.32 & 5.40 & $4.92 \pm 0.00$ & $91.1 \pm 0.0$ \\
\hline & & 8.64 & 9.72 & $8.02 \pm 0.01$ & $82.5 \pm 0.0$ \\
\hline & & 17.28 & 18.36 & $16.19 \pm 0.04$ & $88.2 \pm 0.0$ \\
\hline & & 34.56 & 35.64 & $24.73 \pm 0.06$ & $69.4 \pm 0.1$ \\
\hline \multirow{7}{*}{ methyleugenol } & \multirow{7}{*}{0} & 0.21 & 0.21 & $0.12 \pm 0.00$ & $57.1 \pm 0.0$ \\
\hline & & 0.42 & 0.42 & $0.25 \pm 0.00$ & $59.5 \pm 0.0$ \\
\hline & & 0.84 & 0.84 & $0.56 \pm 0.01$ & $66.7 \pm 0.0$ \\
\hline & & 1.68 & 1.68 & $1.25 \pm 0.00$ & $74.4 \pm 0.0$ \\
\hline & & 3.36 & 3.36 & $2.46 \pm 0.01$ & $73.2 \pm 0.0$ \\
\hline & & 6.72 & 6.72 & $4.18 \pm 0.04$ & $62.2 \pm 0.0$ \\
\hline & & 13.44 & 13.44 & $7.72 \pm 0.07$ & $57.4 \pm 0.1$ \\
\hline \multirow{7}{*}{ myristicin } & \multirow{7}{*}{0} & 2.37 & 2.37 & $1.93 \pm 0.00$ & $81.4 \pm 0.0$ \\
\hline & & 4.74 & 4.74 & $2.98 \pm 0.00$ & $62.9 \pm 0.0$ \\
\hline & & 9.48 & 9.48 & $6.38 \pm 0.00$ & $67.3 \pm 0.0$ \\
\hline & & 18.96 & 18.96 & $12.72 \pm 0.03$ & $67.1 \pm 0.0$ \\
\hline & & 37.92 & 37.92 & $22.22 \pm 0.01$ & $58.6 \pm 0.0$ \\
\hline & & 75.84 & 75.84 & $47.66 \pm 0.03$ & $62.8 \pm 0.0$ \\
\hline & & 151.68 & 151.68 & $95.85 \pm 0.05$ & $63.2 \pm 0.1$ \\
\hline \multirow{7}{*}{ safrole } & \multirow{7}{*}{0} & 1.08 & 1.08 & $0.84 \pm 0.00$ & $77.8 \pm 0.0$ \\
\hline & & 2.16 & 2.16 & $1.38 \pm 0.01$ & $63.9 \pm 0.0$ \\
\hline & & 4.32 & 4.32 & $2.76 \pm 0.00$ & $63.9 \pm 0.0$ \\
\hline & & 8.64 & 8.64 & $5.63 \pm 0.03$ & $65.2 \pm 0.0$ \\
\hline & & 17.28 & 17.28 & $10.32 \pm 0.03$ & $59.7 \pm 0.0$ \\
\hline & & 34.56 & 34.56 & $23.37 \pm 0.04$ & $67.6 \pm 0.0$ \\
\hline & & 69.12 & 69.12 & $45.55 \pm 0.07$ & $65.9 \pm 0.1$ \\
\hline \multirow{7}{*}{ estragole } & \multirow{7}{*}{0.59} & 2.19 & 2.78 & $2.06 \pm 0.00$ & $74.1 \pm 0.0$ \\
\hline & & 4.38 & 4.97 & $3.83 \pm 0.01$ & $77.1 \pm 0.0$ \\
\hline & & 8.76 & 9.35 & $7.07 \pm 0.01$ & $75.6 \pm 0.0$ \\
\hline & & 17.52 & 18.11 & $14.00 \pm 0.02$ & $77.3 \pm 0.0$ \\
\hline & & 35.04 & 35.63 & $27.68 \pm 0.02$ & $77.7 \pm 0.0$ \\
\hline & & 70.08 & 70.67 & $56.14 \pm 0.05$ & $79.4 \pm 0.1$ \\
\hline & & 140.16 & 140.75 & $106.17 \pm 0.06$ & $75.4 \pm 0.1$ \\
\hline
\end{tabular}

Table 6. Application of the optimized MeOH extraction and reversed-phase HPLC to basil leaves, commercial basil sauce and clove samples.

\begin{tabular}{cccccc}
\hline \multirow{2}{*}{ Sample } & \multicolumn{4}{c}{ Amount Found (mg/g) } & \\
& Eugenol & Methyleugenol & Myristicin & Safrole & Estragole \\
\hline basil leaves & $0.27 \pm 0.01$ & $0.07 \pm 0.01$ & ND & ND & $0.72 \pm 0.11$ \\
Galiko basil sauce & $0.12 \pm 0.01$ & $0.004 \pm 0.00$ & ND & ND & $0.07 \pm 0.01$ \\
cloves & $8.71 \pm 0.09$ & ND & ND & ND & ND \\
\hline
\end{tabular}

ND: not detected. 


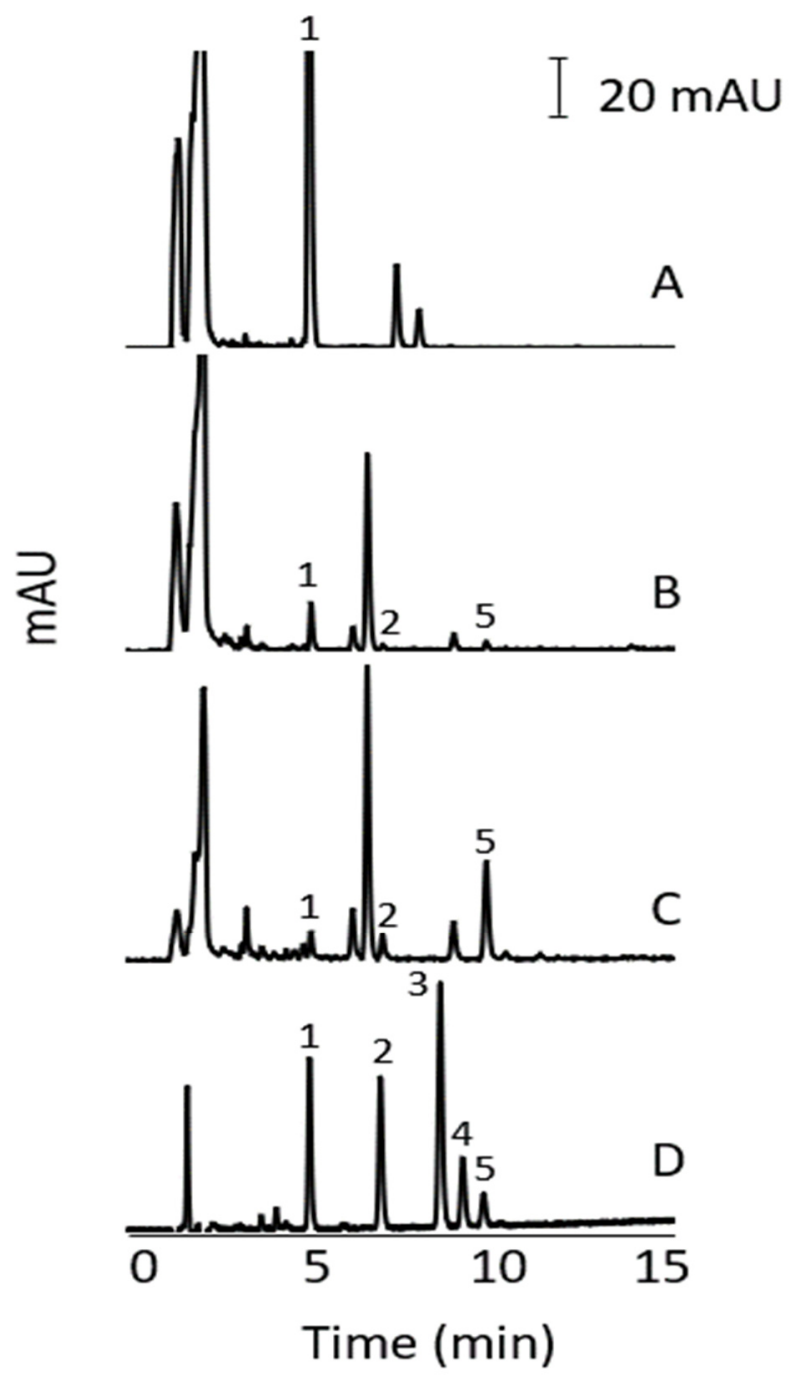

Figure 5. Representative HPLC chromatograms of cloves (A), Galiko basil sauce (B), basil leaves (C), and alkenylbenzenese standard solution (D). Experimental conditions were stated in Section 2.4 and peak identity as in Figure 1.

\section{Conclusions}

In the present work, reversed-phase HPLC and stacking-MEKC methods were developed for the determination of alkenylbenzenes in food flavouring ingredients. The analytical figures of merit determined for reversed-phase HPLC outperformed the stackingMEKC method. The reversed-phase HPLC linear ranges were $\sim 2$ orders of concentration magnitude with correlation coefficients of $>0.997$ for the calibration graphs. The limit of quantitation (LOQ) values obtained for standard solutions were between 0.07 and $0.79 \mu \mathrm{g} / \mathrm{mL}$. The intra- and inter-day repeatability obtained using standard solutions at the LOQ and $8 \times$ LOQ for retention time and peak areas were $<7.0 \%$. Meanwhile, the optimised $\mathrm{MeOH}$ extraction method provided percentage recovery values from 57 to $91 \%$. The analytical methodology that combined $\mathrm{MeOH}$ extraction and reversed-phase HPLC was then successfully applied to actual food flavouring ingredients. The analytical methodology will be implemented to actual food samples in the future. Using an ample number of real samples, we aim to determine the occurrence data and margin of exposure for the alkenylbenzenes. Therefore, we may be able provide guidance on the current potential health risks of these compounds that are ubiquitously found in our foods today. 
Author Contributions: Conceptualization, J.P.Q.; resources, J.P.Q.; writing-original draft preparation, H.N.P.D. and J.P.Q.; writing-review and editing, H.N.P.D. and J.P.Q.; visualization, H.N.P.D.; supervision, J.P.Q.; project administration, J.P.Q.; funding acquisition, J.P.Q. All authors have read and agreed to the published version of the manuscript.

Funding: This research was funded by Australian Research Council [DP180102810,2018].

Conflicts of Interest: The authors declare no conflict of interest.

Sample Availability: Samples of the compounds including eugenol, methyleugenol, myristicin, safrole and estragole are available from the authors.

\section{Abbreviations \\ HPLC High performance liquid chromatography \\ MEKC Micellar electrokinetic chromatography \\ GC Gas chromatography}

\section{References}

1. Martins, C.; Rueff, J.; Rodrigues, A.S. Genotoxic alkenylbenzene flavourings, a contribution to risk assessment. Food Chem. Toxicol. 2018, 118, 861-879. [CrossRef]

2. Mohammadi Nejad, S.; Özgüneş, H.; Başaran, N. Pharmacological and Toxicological Properties of Eugenol. Turk. J. Pharm. Sci. 2017, 14, 201-206. [CrossRef] [PubMed]

3. Scientific Committee on Food. Opinion of the Scientific Committee on Food on Estragole (1-Allyl-4-Methoxybenzene); European Commission Health and Consumer Protection Directorate-General: Brussel, Belgium, 2001; pp. 1-10.

4. Scientific Committee on Food. Opinion of the Scientific Committee on Food on the Safety of the Presence of Safrole (1-Allyl-3,4-Methylene Dioxy Benzene) in Flavourings and Other Food Ingredients with Flavouring Properties; European Commission Health and Consumer Protection Directorate-General: Brussel, Belgium, 2002.

5. Scientific Committee on Food; European Commission. Opinion of the Scientific Committee on Food on Methyleugenol (4-Allyl-1,2Dimethoxybenzene); European Commission Health and Consumer Protection Directorate-General: Brussel, Belgium, 2001.

6. Alajlouni, A.M.; Al-Malahmeh, A.J.; Isnaeni, F.N.; Wesseling, S.; Vervoort, J.; Rietjens, I.M.C.M. Level of Alkenylbenzenes in Parsley and Dill Based Teas and Associated Risk Assessment Using the Margin of Exposure Approach. J. Agric. Food Chem. 2016, 64, 8640-8646. [CrossRef] [PubMed]

7. Alajlouni, A.M.; Al-Malahmeh, A.J.; Wesseling, S.; Kalli, M.; Vervoort, J.; Rietjens, I.M.C.M. Risk assessment of combined exposure to alkenylbenzenes through consumption of plant food supplements containing parsley and dill. Food Addit. Contam.-Part A Chem. Anal. Control Expo. Risk Assess. 2017, 34, 2201-2211. [CrossRef] [PubMed]

8. Suparmi, S.; Wahidin, D.; Rietjens, I.M.C.M. Risk characterisation of constituents present in jamu to promote its safe use. Crit. Rev. Toxicol. 2021, 51, 183-191. [CrossRef]

9. Choong, Y.M.; Lin, H.J. A rapid and simple gas chromatography method for direct determination of safrole in soft drinks. J. Food Drug Anal. 2001, 9, 27-32.

10. Raffo, A.; D'Aloise, A.; Magrì, A.L.; Leclercq, C. Quantitation of tr-cinnamaldehyde, safrole and myristicin in cola-flavoured soft drinks to improve the assessment of their dietary exposure. Food Chem. Toxicol. 2013, 59, 626-635. [CrossRef] [PubMed]

11. Ávila, M.; Zougagh, M.; Escarpa, A.; Ríos, Á. Determination of alkenylbenzenes and related flavour compounds in food samples by on-column preconcentration-capillary liquid chromatography. J. Chromatogr. A 2009, 1216, 7179-7185. [CrossRef] [PubMed]

12. Lee, J.Y.; Park, W. Anti-inflammatory effect of myristicin on RAW 264.7 macrophages stimulated with polyinosinic-polycytidylic acid. Molecules 2011, 16, 7132-7142. [CrossRef] [PubMed]

13. Woehrlin, F.; Fry, H.; Abraham, K.; Preiss-Weigert, A. Quantification of Flavoring Constituents in Cinnamon: High Variation of Coumarin in Cassia Bark from the German Retail Market and in Authentic Samples from Indonesia. J. Agric. Food Chem. 2010, 58, 10568-10575. [CrossRef]

14. Khalil, A.A.; ur Rahman, U.; Khan, M.R.; Sahar, A.; Mehmood, T.; Khan, M. Essential oil eugenol: Sources, extraction techniques and nutraceutical perspectives. RSC Adv. 2017, 7, 32669-32681. [CrossRef]

15. Environment Canada Health Canada. Benzenes, 1,2-Dimethoxy-4-(2-Propenyl)-(Methyl Eugenol); Environment Canada Health Canada: Ottawa, ON, Canada, 2010.

16. Stein, U.; Greyer, H.; Hentschel, H. Nutmeg (myristicin) poisoning-report on a fatal case and a series of cases recorded by a poison information centre. Forensic Sci. Int. 2001, 118, 87-90. [CrossRef]

17. Febrina, A.; Mutakin, M.; Lestari, K.; Levita, J. Determination of Safrole in Ethanol Extract of Nutmeg (Myristica fragrans Houtt) Using Reversed-Phase High Performance Liquid Chromatography. Int. J. Chem. 2014, 6. [CrossRef]

18. Southwell, I.A.; Russell, M.F.; Davies, N.W. Detecting traces of methyl eugenol in essential oils: Tea tree oil, a case study. Flavour Fragr. J. 2011, 26, 336-340. [CrossRef]

19. Cook, W.; Howard, A. The essential oil of Illicium anisatum Linn. Can. J. Chem. 2011, 44, 2461-2464. [CrossRef] 
20. National Toxicology Program. NTP Technical Report on the Toxicology Studies of Myristicin (CASRN 607-91-0) Administered by Gavage to F344/NTac Rats and B6C3F1/N Mice. In Toxicity Report 95; National Toxicology Program: Research Triangle Park, NC, USA, 2019.

21. Marabini, L.; Neglia, L.; Monguzzi, E.; Galli, C.; Marinovich, M. Assessment of Toxicity of Myristicin and 1'-Hydroxymyristicin in HepG2 Cell Line. J. Pharmacol. Toxicol. 2017, 12, 170-179. [CrossRef]

22. Malhotra, S.; Singh, A.P. Medicinal Properties of Ginger (Zingiber Officinale Rosc.); NISCAIR-CSIR: New Delhi, India, 2003.

23. Suparmi, S.; Ginting, A.J.; Mariyam, S.; Wesseling, S.; Rietjens, I.M.C.M. Levels of methyleugenol and eugenol in instant herbal beverages available on the Indonesian market and related risk assessment. Food Chem. Toxicol. 2019, 125, 467-478. [CrossRef]

24. Farag, S.E.A.; Abo-Zeid, M. Degradation of the natural mutagenic compound safrole in spices by cooking and irradiation. Food/Nahr. 1997, 41, 359-361. [CrossRef]

25. Zeller, A.; Rychlik, M. Impact of estragole and other odorants on the flavour of anise and tarragon. Flavour Fragr. J. 2007, 22, 105-113. [CrossRef]

26. Eisenreich, A.; Götz, M.E.; Sachse, B.; Monien, B.H.; Herrmann, K.; Schäfer, B. Alkenylbenzenes in Foods: Aspects Impeding the Evaluation of Adverse Health Effects. Foods 2021, 10, 2139. [CrossRef] [PubMed]

27. Wong, C.; Crystal, K.; Coats, J. Three molecules found in rosemary or nutmeg essential oils repel ticks (Dermacentor variabilis) more effectively than DEET in a no-human assay. Pest Manag. Sci. 2021, 77, 1348-1354. [CrossRef]

28. Carlson, M.; Thompson, R. Liquid chromatographic determination of safrole in sassafras-derived herbal products. J. AOAC Int. 1997, 80, 1023-1028. [CrossRef] [PubMed]

29. Batool, S.; Khera, R.A.; Hanif, M.A.; Ayub, M.A. Bay Leaf. Med. Plants South Asia 2020, 63-74. [CrossRef]

30. Yahyaa, M.; Berim, A.; Nawade, B.; Ibdah, M.; Dudareva, N.; Ibdah, M. Biosynthesis of methyleugenol and methylisoeugenol in Daucus carota leaves: Characterization of eugenol/isoeugenol synthase and O-Methyltransferase. Phytochemistry 2019, 159, 179-189. [CrossRef] [PubMed]

31. Carman, A.S.; Kuan, S.S.; Francis, O.J.; Ware, G.M.; Luedtke, A.E. Rapid Screening Method for Determining Myristicin in Fresh and Frozen Carrots by Gas Chromatography. Anal. Lett. 1985, 18, 1167-1175. [CrossRef]

32. Rivera-Pérez, A.; López-Ruiz, R.; Romero-González, R.; Garrido Frenich, A. A new strategy based on gas chromatography-high resolution mass spectrometry (GC-HRMS-Q-Orbitrap) for the determination of alkenylbenzenes in pepper and its varieties. Food Chem. 2020, 321, 126727. [CrossRef] [PubMed]

33. Dang, H.N.P.; Quirino, J.P. Analytical separation of carcinogenic and genotoxic alkenylbenzenes in foods and related products (2010-2020). Toxins 2021, 13, 387. [CrossRef] [PubMed]

34. Terabe, S.; Otsuka, K.; Ichikawa, K.; Tsuchiya, A.; Ando, T. Electrokinetic Separations with Micellar Solutions and Open-Tubular Capillaries. Anal. Chem. 1984, 56, 111-113. [CrossRef]

35. Yu, R.B.; Quirino, J.P. Ionic liquids in electrokinetic chromatography. J. Chromatogr. A 2021, 1637. [CrossRef] [PubMed]

36. Huhn, C.; Pütz, M.; Pyell, U. Separation of very hydrophobic analytes by micellar electrokinetic chromatography. III. Characterization and optimization of the composition of the separation electrolyte using carbon number equivalents. Electrophoresis 2008, 29, 783-795. [CrossRef]

37. Ranasinghe, M.; Quirino, J.P. Can we replace liquid chromatography with the greener capillary electrophoresis? Curr. Opin. Green Sustain. Chem. 2021, 31. [CrossRef]

38. Laing, T.D.; Marenco, A.J.; Moore, D.M.; Moore, G.J.; Mah, D.C.W.; Lee, W.E. Capillary electrophoresis laser-induced fluorescence for screening combinatorial peptide libraries in assays of botulinum neurotoxin A. J. Chromatogr. B Anal. Technol. Biomed. Life Sci. 2006, 843, 240-246. [CrossRef] [PubMed]

39. Ranasinghe, M.; Karunaratne, H.; Quirino, J.P. Sweeping-micellar electrokinetic chromatography versus reversed phase liquid chromatography for the determination of coumarin in curry. J. Chromatogr. A 2021, 1657. [CrossRef]

40. Simó, C.; Moreno-Arribas, M.V.; Cifuentes, A. Ion-trap versus time-of-flight mass spectrometry coupled to capillary electrophoresis to analyze biogenic amines in wine. J. Chromatogr. A 2008, 1195, 150-156. [CrossRef] [PubMed]

41. Quirino, J.P.; Terabe, S. Exceeding 5000-fold concentration of dilute analytes in micellar electrokinetic chromatography. Science 1998, 282, 465-468. [CrossRef] [PubMed]

42. Quirino, J.P.; Terabe, S. Sweeping of analyte zones in electrokinetic chromatography. Anal. Chem. 1999, 71, 1638-1644. [CrossRef]

43. Quirino, J.P.; Terabe, S. On-line concentration of neutral analytes for micellar electrokinetic chromatography. 5. Field-enhanced sample injection with reverse migrating micelles. Anal. Chem. 1998, 70, 1893-1901. [CrossRef]

44. Liu, Z.; Sam, P.; Sirimanne, S.R.; McClure, P.C.; Grainger, J.; Patterson Jr, D.G. Field-amplified sample stacking in micellar electrokinetic chromatography for on-column sample concentration of neutral molecules. J. Chromatogr. A 1994, 673, 125-132. [CrossRef]

45. Gursale, A.; Dighe, V.; Parekh, G. Simultaneous Quantitative Determination of Cinnamaldehyde and Methyl Eugenol From Stem Bark of Cinnamomum zeylanicum Blume Using RP-HPLC. J. Chromatogr. Sci. 2010, 48, 59-62. [CrossRef] 